editions of :-“Electricity in its Application to Telegraphy," by T. E. Herbert; " Central Station Electricity Supply," by A. Gay and C. H. Yeaman: "The Alternating-Current Circuit and Motor," by W. P. Maycock ; and "Radium," by S. R. Bottone.

\section{LINIVERSITY AND EDUCATIONAL INTELLIGENCE.}

Cambridge.--An Arnold Gerstenberg studentship will be offered for competition in the Michaelmas term of 1906. The studentship will be awarded by means of essays. Every candidate must send on or before October I, 1906, an essay on one of the subjects printed below addressed to Dr. James Ward, Trinity College. The studentship, which will be of the annual value of nearly gol., will be tenable for two years, upon the condition that at the end of the first year the student's progress in philosophical study is deemed satisfactory by the board of managers. The subjects for essays are:-(1) a philosophical discussion of the doctrine of energy and particularly of the new theory of energetics; (2) a critical examination of Descartes' philosophy of nature; (3) the relation of mathematics and the theory of probability to physics; (4) the theory of psychophysical parallelism; (5) the scope and methods of comparative psychology; (6) the philosophical import of post-Darwinian theories of natural selection.

The principal and the professors at McGill University, Montreal have nominated Mr. L. V. King, a student in the faculty of arts, to the Canadian scholarship lately established at Christ's College.

An exhibition of $50 l$. a year tenable for two years is offered by the governing body of Emmanuel Ccllcge to an advanced student commencing residence at the college in October, 1905. Applications should be sent to the master of Emmanuel (from whom further particulars may be obtained) not later than October 1 .

The local examinations and lectures syndicate is about to elect an assistant secretary for the department of the local lectures. The appointment will be in the first instance for one year. The stipend will be $15 \mathrm{ol}$. in an ordinary year, and $200 \%$. in those years in which summer meetings are held. Graduates of the university who desire to offer themselves as candidates are requested to send their names before May 8 to the Rev. D. H. S. Cranage.

THE London School of Tropical Medicine has been admitted as a school of the University of London in the faculty of medicine in tropical medicine only.

The committee of the Liverpool School of Tropical Medicine has appointed Mr. R. T. Newstead lecturer in economic entomology and parasitology.

THE fourth annual students' soirée of the Sir John Cass Iechnical Institute will be held in the institute, Jewry Street. Aldgate, E.C., on Saturday, March 18. Exhibits and demoristrations referring to the work of the various departments form part of the programme.

IT is reported, says Science, that $\mathrm{Mr}$. Andrew Carnegie has offered to give $100,000 l$. to the University of Virginia on the condition that the authorities of the institution raise a similar amount from other sources, and that the late James C. Carter, the eminent New York lawyer, has bequeathed 40,oool. to Harvard University. Science also states that at the first of the winter convocations of the George Vlashington University a gift of property, estim xted to be worth $20,000 l$., was announced for the establish nent of a chair and course of graduate study on the history of civilisation. Various sums of money raised by the trustees and alumni association, aggregating $55,000 l$, were also announced.

A Commission was appointed a few years ago to inquire into the condition of manual and practical instruction in Irish primary schools, and, as the result of the recommendations made by this Commission, instruction in elementary experimental science was introduced into the primary schools of Ireland. The results of this teaching have, in the opinion of competent authorities, been in every way satisfactory. Not only has the educational value of experimental science again been demonstrated, but its beneficial effects on the progress of Ireland's industries and agriculture have been made clear. Notwithstanding the success which naturally has followed the introduction of practical instruction in scientific principles into Irish elementary schools, the Treasury has refused to renew the small grant required to meet the necessary expenditure, and the work of organising science instruction in the schoolsafter four years-is being stopped. It is difficult indeed to understand so retrograde a policy. The incompleteness of all schemes of education which ignore the claims of practical instruction in the fundamental facts of science has been demonstrated repcatedly: the connection between American and German industrial success and the scientific systems of education established in these countries has become familiar to all interested in their country's welfare, so that no excuse-not even the urgent need of economy in national expenditure-can justify this action of the Treasury. It is to be hoped earnestly that steps may yet be taken to avert what would be nothing short of a calamity to Ireland, and that the work, which has begun so auspiciously under the present organisers of science instruction, instead of being stopped may be broadened and extended.

IT is stated in the Times that the committee, presided over by Mr. Haldane, M.P., appointed to consider the allocation of the increased grant-in-aid of education of a university standard in arts and science has now finished its inquiry. Excluding $9000 l$, to be allctted later in the financial year, the committee proposes that the sum of $45,000 l$. (making a total grant of $54,000 l$.) be allotted as follows:-Manchester, 60ool.; University College, London, $5000 \mathrm{l}$; Liverpool, 500ol.; Birmingham, 4500l.; Leeds, $4000 l$.; King's College, London, $3900 l$. ; Newcastle-on-Tyne $3000 l$.; Nottingham, 290ol.; Sheffield, 230ol.; Bedford College, London, 2000 l.; Bristol, 2000l.; Reading, 1700l.; Southampton, I7ool.; Dundee, roool. The committee expresses the view that the time has come for making a new departure in the principle on which State assistance is to be given to the highest education. It is recommended that a moderate sum should be set aside for distribution by way of payment to post-graduate students from the university colleges who devote themselves for one, two, or three years to special problems; and that to ensure the money being applied most efficiently to the stimulation of individual study, as distinguished from the general purposes of the college to the development of which other sums out of the grant are directed, the distribution should assume the form of a grant made directly to the student on the advice of some impartial authority. It is also suggested that the grant-in-aid should in future be made to a committee, instead of to the colleges direct, and that this committee should make an annual report to the Treasury, to be laid before Parliament. In conclusion the committee urges the necessity of leaving to the advisory committee discretion to deal with particular circumstances as they arise.

\section{SOCIETIES AND ACADEMIES. \\ Lonvon.}

Royal Society, February 9.- "On the Stellar Line near $\lambda$ 4686." By Sir Norman Lockyer, K.C.B., F.R.S., and F. E. Baxandall. A.R.C.Sc

In this paper the authcrs direct attention to a wellmarked line of unknown origin which appears in one of the Kensington photographs of the helium spectrum near $\lambda 4686$.

It is shown that a conspicuous line near the same wavelength occurs in the spectra of the chromosphere, nebulæ, bright-line stars, certain Orion stars, and in $\zeta$ Puppis, the star the spectrum of which was found by Prof. Pickering to contain a new series of lines which he considered to belong to hydrogen.

The mean wave-length of the stellar line, as derived from the available published records, is shown to agree very closely with the wave-length of the line in the laboratory spectrum, and the authors conclude that the identity of the two lines is probably a real one.

Rydberg has shown that the line near $\lambda_{4} 686$ is the first line in the principal series of hydrogen, and the authors of the present paper consider that the "strange" line in 